* Doutorando em Direito Político e Econômico na Universidade Presbiteriana Mackenzie (Bolsista Mackenzie) e membro do grupo de pesquisa Estado e Economia no Brasil. Mestre em Direito Obrigacional Público e Privado pela Universidade Estadual Paulista "Júlio de Mesquita Filho"- UNESP (Bolsista FAPESP), Especialista em Direito Processual pela Universidade do Estado de Minas Gerais, Especialista em Direito Penal e Processual Penal pela UCDB, Especialista em Direito Empresarial e Advocacia Empresarial (Anhanguera-Uniderp) e MBA em Gestão Empresarial pelo UNESC. Professor de graduação e pós-graduação e em cursos preparatórios para concursos. Advogado. E-mail:vvilela@hotmail. com.

\section{A REGULAÇÃO E A VIABILIDADE DE UMA AGÊNCIA REGULADORA PARA O ENSINO SUPERIOR BRASIL}

\author{
THE REGULATION AND THE \\ FEASIBILITY OF A REGULATORY \\ AGENCY FOR HIGHER EDUCATION \\ BRAZIL
}

\section{Danilo Vieira Vilela*}

Como citar: VILELA, Danilo Vieira. Aregulação e a viabilidade de uma agência reguladora para o ensino superior Brasil. Revista do Direito Público, Londrina, v. 11, n. 3, p.80-112, dez. 2016. DOI: $10.5433 / 1980-511 X .2016 v 11 n 3 p 80$. ISSN: 1980-511X.

Resumo: O presente artigo tem como objetivo discutir a atuação do Estado na regulação do ensino superior no Brasil a partir de uma pesquisa bibliográfica. Parte da análise do modelo de Estado estabelecido na Constituição de 1988, enfatizando-se a adoção das agências reguladoras independentes, modelo importado dos EUA, cuja aclimatação ainda não se deu por completo no ordenamento brasileiro. A seguir é traçado um panorama do Ensino Superior no país, destacando-se a prevalência dos agentes econômicos privados nesse setor. Ao final é analisada a viabilidade da criação de uma agência reguladora, concluindo-se no sentido 
de que, apesar da inquestionável necessidade de o Estado disciplinar o Ensino Superior, a adoção do modelo de agências reguladoras não se apresenta como a alternativa mais viável no momento, ante ao relativo fracasso de outras agências cuja atuação é criticada em razão da sua imprecisa delimitação, sobretudo quando em confronto com interesses privados ou com as competências constitucionais dos demais poderes. Assim, até que o Estado consiga especificar com precisão o que espera de suas agências reguladoras, bem como estabelecer mecanismos que impeçam sua captura, entende-se mais prudente a manutenção da atividade regulatória na competência da estrutura do Ministério da Educação.

Palavras-chave: Estado Regulador. Ensino Superior. Agências Reguladoras.

Abstract: Using the literature research method, this paper discusses the State's role in regulating higher education in Brazil. Firstly, this study analyzes the Brazilian State's model, which was established by the Brazilian Federal Constitution of 1988; however, the adoption of independent regulatory agencies - a model imported from the United States of America has not been entirely adopted by the Brazilian system. Sequentially, this research draws a panorama of Brazil's higher education; therefore, highlighting the prevalence of private economic agents acting within this sector. In conclusion, this paper examines the 
feasibility of establishing a regulatory agency and concludes that despite the unquestionable need for the regulation of Higher Education, the adoption of this model is not the solution or a viable working alternative. Despite that, compared to the relative failure of other agencies, which work is criticized because of its imprecise definition, the mismatch of private interests, and the constitutional powers of the other branches; the State should at least specify the regulatory agency's expectations and establish mechanisms that prevents failure. Therefore, it should be a means for more prudent work that helps in maintaining regulatory activity in the jurisdiction of the Ministry of Education.

Keywords: State Governor. Higher Education. Regulation. 


\section{INTRODUÇÃO}

O ensino superior, conforme diretrizes constitucionais, é um serviço público que pode ser prestado diretamente pelo Estado ou por agentes econômicos privados, desde que observadas normas gerais da educação nacional e mediante autorização e avaliação de qualidade pelo Poder Público.

Com base nisso, observou-se, no país, um vertiginoso crescimento do número de instituições de ensino superior (IES) privadas nas últimas décadas, possibilitando o acesso de milhões de jovens e adultos a esse nível de ensino, situação ainda favorecida por políticas públicas de incentivo, tais como o Programa Universidade para Todos (Prouni) e a facilitação do acesso ao Fundo de Financiamento Estudantil (Fies).

Entretanto, esse crescimento, é responsável por maquiar parte da realidade brasileira já que, voltadas exclusivamente a critérios mercadológicos, muitas dessas IES vêm ofertando ensino qualidade precária, privilegiando-se a condição do aluno enquanto consumidor, ao invés de ater-se à formação de um quadro de profissionais críticos e bem qualificados para a condução dos rumos políticos, culturais, sociais e econômicos do país nas próximas décadas.

Ante a esse quadro, o presente artigo volta-se à discussão do modelo de regulação a ser adotado pelo país no setor da Educação Superior, questionando-se a necessidade de se criar um novo ente com o propósito de centralizar o papel regulador do Estado.

Parte-se, dessa forma, da análise do papel do Estado perante a ordem econômica a partir do texto constitucional e das transformações políticas e econômicas oriundas da Reforma do Estado ocorrida nos 
anos 90, durante o governo do Presidente Fernando Henrique Cardoso.

A seguir apresenta-se um perfil do ensino superior brasileiro, evidenciando-se a predominância da oferta de vagas pelo setor privado para, ao final, analisar a viabilidade da criação de uma agência independente para regular o Ensino Superior no Brasil.

\section{A REGULAÇÃO NA CONSTITUIÇÃO DE 1988}

A Revolução Industrial, ainda no século XIX, mesmo que não tenha transformado de forma homogênea todas as economias, certamente foi transformadora de todas elas, sobretudo ao transferir o poder político à classe empresarial que, com o advento do consumo em massa e com as mudanças tecnológicas, conduziu ampla expansão econômica. Contudo, tal poder econômico acabou também por demonstrar seu poder em relação à classe trabalhadora, ao passo que o Estado mantinha-se omisso ante a essa disputa que considerava, exclusivamente, privada (BAGNOLI, 2009, p. 30-33).

Contudo, progressivamente, esse modo de produção amparado pelo Estado liberal, e caracterizado pela autorregulação, mostrou-se insustentável, despertando acirradas críticas oriundas desde o marxismo do "Manifesto do Partido Comunista" (1948) até a doutrina católica com a Encíclica Rerum Novarum, de 1891. Nesse sentido:

A autorregulação do mercado pela mão invisível da concorrência regida pela lei da oferta e da procura, como apresentou Adam Smith, representa o ideal da matéria concorrencial e do controle do poder econômico. Contudo, a história mostrou que a ordem econômica não se estabelece de forma ideal com o poder econômico se autocontrolando, ou seja, os 
agentes econômicos atuando num mercado sem a fiscalização e disciplina do Estado. (BAGNOLI, 2013, p. 6).

Nesse sentido, propunha-se uma maior atuação do Estado na economia, com vistas a coibir abusos dos agentes econômicos e a estabilizar as frágeis relações sociais que tinham, no proletariado, a parcela mais frágil da sociedade, alvo de uma rígida carga de trabalho sem que, em contrapartida, pudesse contar com garantias de acesso ao mínimo necessário à sobrevivência digna.

Nessa perspectiva é que a segunda década do século XX traria importantes avanços, até hoje sentidos na sociedade e no Direito em quase todo o mundo, com a Constituição Mexicana (1917) e da Alemanha (Constituição de Weimar de 1917) e com a Revolução Russa (1917), cujos resultados diretos ou indiretos seriam a atribuição da "qualidade de direitos fundamentais aos direitos trabalhistas, além das liberdades individuais e direitos políticos." (BAGNOLI, 2013, p.12).

Assim, as constituições supracitadas, de forma flagrante visavam o amortecimento do conflito de classes (GRAU, 2007, p. 43), observando-se, na Constituição de Weimar, pela primeira vez, o Direito Econômico, qual seja, “o Estado, em sua lei maior, ditando as regras e princípios para que o fenômeno econômico no mercado encontrasse limites e garantias para atender a sociedade e assegurar a justiça social". (BAGNOLI, 2013, p. 13).

No Brasil, a primeira constituição a trazer disposições sobre a economia, foi a de 1934, inspirada pela Constituição germânica (TAVARES, 2006, p. 94). A Constituição de 1937, mesmo de caráter autoritário, legitima a intervenção do Estado na economia para suprir 
as deficiências da iniciativa individual e para coordenar os fatores de produção, evitando conflitos entre si. Já em 1946, adotando-se a técnica da Constituição Econômica (título V), a carta constitucional admitia a intervenção do Estado no domínio econômico e o monopólio de determinadas atividades ou indústrias, tendo como base o interesse público e, como limite, os direitos fundamentais (SOUZA, 2005, p. 215-217).

Seguindo a esteira da Carta de 1946, a Constituição de 1967 estabeleceu princípios fundamentais do ordenamento econômico, influenciada pela doutrina social da Igreja Católica enunciada na Encíclica Mater et Magistra de João XXIII (1961). Previa, dentre outras disposições de natureza econômica, que "às empresas privadas compete preferencialmente, com o estímulo e apoio do Estado, organizar e explorar as atividades econômicas" (art. 163), perspectiva reiterada pela Emenda Constitucional n. 1, de 1969, que evidenciava a finalidade da ordem econômica como sendo a realização do desenvolvimento nacional (TAVARES, 2006, p. 94).

Segundo Gilberto Bercovici, a Constituição Econômica não é uma inovação do constitucionalismo social do século XX, já que estaria presente em todas as Constituições, inclusive nas liberais do século XVIII e XIX. Contudo, no século XX, elas "não pretendem mais receber a ordem econômica existente, mas querem alterá-la. Elas positivam tarefas e políticas a serem realizadas no domínio econômico e social para atingir certos objetivos" (BERCOVICI, 2005, p. 32-33).

Ou seja, a Constituição Econômica "quer alterar a ordem econômica existente, rejeitando o mito da autorregulação do mercado" e buscando a "configuração econômica do político pelo Estado" (BERCOVICI, 2005, p. 33-34). Nesse sentido é que a Constituição 
Federal de 1988, ao disciplinar a atuação do Estado no domínio econômico, traçam um modelo não mais de um Estado "agente econômico, monopolista, em muitas situações, tampouco de um estado ausente nos padrões liberais, deixando que a concorrência entre agentes privados por si só regulasse a economia" (BAGNOLI, 2013, p. 86).

Esse modelo, disciplinado pela Constituição de 1988, evidencia a subsidiariedade da atuação estatal na economia, transformando-o em garantidor e regulador de vários serviços públicos que, historicamente, havia prestado de maneira direta. Ou seja, transfere a execução (mas não a titularidade) de serviços públicos a empresas privadas concessionárias, passando a exercer as funções de planejamento, regulação e fiscalização (BARROSO, 2005, p.7).

Essa regulação ocorre de três principais formas, conforme destaca Alexandre Santos de Aragão:

(a) a regulação dos monopólios, quando a competição e restrita ou inviável, evitando que eles lesem a economia popular, controlando os preços e a qualidade dos serviços ou produtos; (b) regulação para a competição, como forma de assegurar a livre concorrência no setor privado e, no caso de atividades econômicas sensíveis ao interesse público, o seu direcionamento na senda deste; e (c) regulação dos serviços públicos, assegurando a sua universalização, qualidade e preço justo". (ARAGÃO, 2006, p. 25).

\section{AREFORMA DO ESTADO EASAGÊNCIAS REGULADORAS NO BRASIL}

Ante a esse novo modelo, não mais de Estado prestador, mas de Estado regulador já estampado na Constituição Federal de 1988 (art. 
174), somado à alegada ineficiência do Estado na prestação de serviços públicos, os primeiros governos democraticamente eleitos após o regime militar iniciaram, no Brasil, um processo de diminuição da atuação direta do Estado na economia, ideia que encontra seu ápice no Plano Diretor da Reforma do Aparelho do Estado (PDRAE), de 1995.

Buscava-se, assim, adequar a "máquina estatal" ao papel de regulador, constitucionalmente atribuído ao Estado, exigindo-se, para tanto, a substituição de um modelo burocrático por um modelo gerencial, pautado pela eficiência nos resultados e não pelo apego absoluto a uma legalidade ineficiente e custosa. Nesse sentido:

O modelo gerencial procurou dissolver as fronteiras entre o público e o privado, reforçando a criatividade e a inovação em detrimento do controle de procedimentos, ou, na linguagem importada, procurou-se substituir a rule-based pela performance-based accountability (prestação de contas baseada nas regras pela baseada no desempenho). (NOHARA, 2012, p. 7).

Essa proposta, liderada pelo então Ministro Luiz Carlos Bresser Pereira, culminaria com a lei 9.491 de 9 de setembro de 1997 que alterou o Programa Nacional de Desestatização instituído pela lei 8.031 de 12 de abril de 1990, tendo como um de seus principais objetivos "reordenar a posição estratégica do Estado na economia, transferindo à iniciativa privada atividades indevidamente exploradas pelo setor público" (art. $\left.1^{\text {o }}, \mathrm{I}\right)$ e "contribuir para a reestruturação econômica do setor público, especialmente através da melhoria do perfil e da redução da dívida pública líquida".

Assim, a redução do papel do Estado e a transferência de 
atividades para o setor privado, sobretudo através das desestatizações, possibilitou que o mercado recebesse novos entrantes, acirrando a concorrência, mas mantendo a condição vulnerável do consumidor, fatores suficientes para a criação, seguindo-se o modelo estadunidense, das chamadas "agências reguladoras independentes" que, por sua vez, caracterizam-se como autarquias especiais, compondo a administração indireta do Estado, configurando-se, portanto, como uma forma de intervenção indireta do Estado no domínio econômico (DEL MASSO, 2013, p. 103).

Dessa forma, a atuação das agências reguladoras, ao lado de outros entes que também exercem a regulação, tais como Banco Central do Brasil (Bacen), a Superintendência de Seguros Privados (SUSEP), a Comissão de Valores Mobiliários (CVM) e o Conselho Nacional de Autorregulamentação Publicitária (Conar) (BAGNOLI, 2013, p. 147-148) evidencia a subsidiariedade da atuação estatal na economia, ressaltando o seu papel de regulador.

Não obstante a regulação ser tradicionalmente associada ao setor de serviços públicos, tais como telecomunicações, energia e transportes, também alcança atividades econômicas em sentido estrito que apresentam elevado grau de relevância social, tais como saúde e petróleo, pressupondo, em regra, a criação de entes independentes responsáveis pela implementação de políticas públicas e supervisão da atividade desenvolvida por particulares (CUÉLLAR, 2008, p. 35).

Conforme já destacado, a criação do modelo de agências reguladoras no país decorre, mais uma vez, da tentativa de se incorporar institutos estrangeiros à realidade nacional, já que, nem mesmo a Constituição Federal, em nenhum momento, utiliza-se da expressão "agência reguladora", cunhada pelo legislador infraconstitucional a 
partir da ideia de regulatory agencies ou independet regulatory agencies, utilizada nos Estados Unidos da América.

Contudo, conforme explicita Irene Nohara (2012, p. 125), o sistema brasileiro de agências reguladoras, apesar de ter sido inspirado no modelo estadunidense, com ele comporta significativas diferenças, sobretudo porque lá tais agências são "criadas por leis que lhes outorgam poderes do legislador e cuja atuação é condicionada pelo controle de metas do Congresso".

Já no Brasil, não obstante serem criadas por lei, não há essa transferência de competências por parte do Poder Legislativo às agências reguladoras, resultando em críticas e dúvidas quanto aos limites da atuação dessas autarquias especiais responsáveis pela regulação de setores da economia brasileira (não obstante existirem agências multissetoriais).

Como forma de solucionar a tanto a legitimidade quanto o alcance da atuação das agências reguladoras, prevalece o entendimento segundo o qual as normas por ela editadas devem ser de natureza eminentemente técnica, obedecendo às diretrizes básicas fixadas por lei específica do setor regulado. Ou seja, é imprescindível que a lei possua um conteúdo mínimo, ao qual a norma editada pela agência reguladora deve obediência, sob o risco de se estar diante da delegação propriamente dita da função legislativa, de evidente inconstitucionalidade. Em suma, no exercício da sua "discricionariedade técnica", a agência reguladora deve ter seu poder normativo limitado, condicionado e conformado pela lei (ALEXANDRINO, 2013, p. 173).

Além da atividade normativa, visando disciplinar a atuação do setor regulado e considerando-se que "a noção de regulação está vinculada à ideia de provocar a alteração do comportamento dos particulares" (CUÉLLAR, 2008, p. 61), as agências reguladoras também 
desempenham atividades fiscalizatórias, sancionatórias e julgadoras, além de representarem importante instrumento de proteção do consumidor/ usuário.

O fundamento da atividade fiscalizatória dependerá da agência. Assim, sendo reguladora do serviço público, terá como fundamento o dever inerente ao Poder Concedente; sendo reguladora da exploração privada de monopólio ou bem público, fundamentar-se-á no contrato e, por fim, caso a agência reguladora atue perante atividade econômica privada, sua atividade fiscalizatória será fundamentada pelo exercício do poder de polícia (BAGNOLI, 2013, p. 133).

A competência sancionatória é consequência lógica da atividade fiscalizatória, as quais, legitimadas a partir de sua procedimentalização, devem ser exercidas de forma independente, neutra e imparcial, apolítica e técnica (CUÉLLAR, 2008, p. 53). As sanções a serem aplicadas pelas agências reguladoras hão de ser de natureza administrativa, inadmitindose a criação de qualquer tipo penal como decorrência da atividade reguladora das agências. Assim, a modalidade de sanção mais comum é a pecuniária, podendo ser de outra ordem, como advertências, suspensão ou revogação de concessão, permissão ou autorização, e conformidade com a legislação pertinente (CUÉLLAR, 2008, p. 68).

No exercício da atividade julgadora, compete às agências decidir, em esfera administrativa, os conflitos entre os agentes presentes no mercado regulado: delegatários, Poder Concedente e usuários, buscando, sempre que possível, uma solução consensual. Nesse sentido:

[...] deve-se destacar que, sempre antes de decidir, deve a agência reguladora flexibilizar o quanto puder dentro dos limites assegurados e definidos em lei para buscar o consenso e a conciliação com o ente 
e os agentes regulados, seja na fixação de preços ou tarifas, acesso a redes e informações, tarifas de interconexão, dentre outras peculiaridades da atividade regulada. (BAGNOLI, 2013, p. 134).

Toda essa atividade regulatória, a ser desenvolvida pelas agências reguladoras, só será eficiente se atender, de fato, ao requisito da independência, o que deve ser observado sob três aspectos: funcional, caracterizando-se pela inoponibilidade de recursos hierárquicos impróprios de suas decisões; financeira, decorrente da possibilidade de a agência gerir seus próprios recursos e dos agentes, consequência da garantia de seus mandatos (MOREIRA NETO, 2003, p. 170).

Porém, é justamente nesses aspectos que representariam a independência da agência reguladora, que se encontram as maiores críticas. Alerta Oliveira (2009, p. 163) no sentido de que "a desconfiança em relação ao modelo regulatório tem como consequência a ampliação do controle exercido pelos poderes constituídos em relação aos atos das agências".

Assim, a possibilidade de que, das decisões emanadas das agências reguladoras, sejam interpostos recursos hierárquicos impróprios, conforme Parecer AGU 51/06, no caso envolvendo a Agência Nacional de Transportes Aquaviários (ANTAQ), representa um enfraquecimento do modelo de agências adotado no Brasil em relação ao Poder Executivo, o que reduz sua independência no exercício da atividade reguladora (NOHARA, 2011, p. 559).

A autonomia financeira deveria ser assegurada pelas taxas regulatórias que as agências reguladoras cobram dos entes regulados e por dotações orçamentárias provenientes do orçamento dos Ministérios a que se vinculam. Contudo, conforme denuncia Bagnoli (2013, p. 137), 
tais agências vêm sofrendo cortes em seus orçamentos, o que gera uma deterioração de suas atividades.

Já a independência dos seus agentes, é buscada através de vários aspectos. Primeiramente cumpre destacar que a nomeação dos seus dirigentes dá-se por ato complexo, que envolve a indicação pelo Poder Executivo e a respectiva aprovação pelo Poder Legislativo (Senado Federal, no âmbito Federal). Além disso, tais dirigentes, além de comporem uma diretoria colegiada, devem contar com a habilitação profissional e a capacidade técnica necessárias ao desempenho da atividade. Por fim, tais dirigentes contam com mandatos fixos, não podendo ser "demitidos de forma injustificada, garantindo-se, assim, uma estabilidade provisória aos diretores e uma consequente estabilidade ao próprio funcionamento das agências" (CUÉLLAR, 2008, p. 86).

Contudo, não obstante a presença de instrumentos para se buscar a independência dos diretores das agências reguladoras, tais fatores não foram suficientes para afastar indevidas influências dos agentes econômicos regulados sobre as agências reguladoras, de modo a beneficiarem-se, seja em relação aos consumidores usuários, sejam em relação ao próprio Estado.

É o que a moderna doutrina denomina de teoria da captura ("capture theory", na doutrina americana), pela qual se busca impedir uma vinculação promíscua entre a agência, de um lado, e o governo instituidor ou os entes regulados, de outro, com flagrante comprometimento da independência da pessoa controladora. (CARVALHO FILHO, 2014, p. 495).

Conclui-se, dessa forma que, apesar de as agências reguladoras não causarem qualquer violação à ordem constitucional brasileira, nem 
tampouco ao Estado Democrático de Direito (SCHIRATO, 2012, p. 533), vem sofrendo interferência política do governo, fazendo com que o sistema idealizado perca sua pureza e vocação (CARVALHO FILHO, 2014. p. 496) bem como são alvos fáceis da captura pelos setores regulados.

Assim, ainda que o modelo adotado pelo direito brasileiro seja idealmente adequado, o fato é que ainda não houve uma verdadeira "aclimatação" das agências reguladoras no ordenamento jurídico brasileiro, na feliz expressão cunhada por Oliveira (2009, p. 158). Nesse mesmo sentido:

Ora, sabemos que as 'agências independentes' não são independentes. E a regulação no Brasil não significa a "republicização" do Estado. Pelo contrário, a regulação significou o desmonte da estrutura do Estado, o sucateamento do Poder Público e o abandono de qualquer possibilidade de implementação de uma política deliberada de desenvolvimento nacional. (BERCOVICI, 2005, p. 85).

\section{O ESTADO ATUAL DO ENSINO SUPERIOR NO BRASIL}

A educação foi disciplinada na Constituição Federal dentro da Seção I do Capítulo III do Título VIII (Da ordem social), juntamente com a Cultura e o Desporto. Para efeitos da análise proposta por esse trabalho, merece destaque o art. 209, segundo o qual:

Art. 209. O ensino é livre à iniciativa privada, atendidas as seguintes condições:

I. cumprimento das normas gerais da educação nacional; 
II. autorização e avaliação de qualidade pelo Poder Público. (BRASIL, 1988, p. 72).

Dessa forma, tem-se que a iniciativa privada pode oferecer o ensino em todos os seus níveis e modalidades, já que a expressão "ensino" foi empregada com conotação aberta, desde que cumprindo as regras gerais da educação nacional, tais como aquelas previstas na Lei de Diretrizes e Bases da Educação Nacional, como também os princípios contidos no art. 206 da Constituição da República. Por outro lado, os estabelecimentos de ensino sujeitam-se à autorização e avaliação de qualidade pelo Poder Público (SILVA, 2009, p. 795).

Além disso, a oferta de serviços educacionais deve ser pautada pelo respeito aos princípios informadores da Educação, quais sejam: universalidade, igualdade, pluralismo, gratuidade do ensino público, valorização dos profissionais, gestão democrática da escola e padrão de qualidade (MENDES; COELHO; BRANCO, 2009, p. 1421).

Em relação ao ensino superior, é notório o vertiginoso aumento no número de vagas, cursos e instituições ocorrido nas últimas décadas graças, inclusive, a programas de inclusão de jovens de baixa renda nas universidades, tais como o Prouni e a facilitação de acesso ao FIES.

Nesse sentido, no ano de 2012 o Censo da Educação Superior feito pelo MEC/Inep, contabilizava a existências de 103 Instituições de Ensino Superior (IES) federais, 116 estaduais, 85 municipais e 2.112 privadas, o que representa uma variação de 4,4\% em relação aos três anos anteriores (CENSO, 2014, p. 49).

O mesmo Censo constatou que em 2012, 14.075.376 alunos estavam matriculados em cursos de graduação (2014, p.57) dos quais 1.050.413 concluiriam seus cursos naquele ano (CENSO, 2014, p. 69). 
Em relação aos cursos de graduação, cumpre destacar que segundo esses mesmos dados, 66\% encontravam-se em IES da rede privada, que equivaliam a $87,4 \%$ do total de instituições em funcionamento no ano de 2012. Já as IES públicas, mesmo representando apenas $12,6 \%$ do total de instituições, respondem por $34 \%$ dos cursos de graduação ofertados (CENSO, 2014, p. 79).

Essa absoluta superioridade numérica das IES privadas também é decorrência dos rumos políticos e econômicos do Brasil nos anos 90, nos quais, buscando ajustar-se à nova ordem mundial, diversos setores, dentre eles o ensino superior, passaram por uma reconfiguração segundo a ótica e a racionalidade econômicas (SILVA JR.; SGUISSARDI, 2001, p. 193-194).

De lá pra cá, houve um progressivo aumento da participação das IES privadas na Educação Superior do país, sobretudo em razão de uma relativa estagnação das IES públicas durante décadas, situação apenas alterada nos últimos anos.

Contudo, se por um lado o aumento da oferta de vagas de graduação e a ampliação do número de instituições de ensino superior proporcionam um avanço em termos do acesso de jovens e adultos à formação superior, é notório que essa expansão não foi acompanhada por uma evolução qualitativa. Ou seja, o maior acesso a cursos superiores não representa uma qualificação a níveis satisfatórios, da população brasileira, ante ao baixo nível dos cursos ofertados, o que passa pelas más condições de trabalho dos professores, por problemas decorrentes de falhas nas etapas anteriores de ensino e até mesmo por deficiências na infraestrutura das IES.

Observa-se, dessa forma, um absoluto privilégio para o ensino, ainda que muitas vezes deficitário, em prejuízo da pesquisa e da extensão 
que, juntos compõem o tripé do ensino superior no Brasil.

Considerando a participação de agentes econômicos privados na oferta do ensino superior no país, cumpre ao Estado, além de prestálo diretamente através da IES públicas, regular a atividade seguindo critérios estabelecidos em lei, sobretudo na Lei de Diretrizes e Bases da Educação Nacional (LDB - lei 9.394/96) que cuida da Educação Superior no capítulo IV, artigos 43 a 57.

Assim, a LDB fixou as regras do ensino superior, tais como:

[...] a frequência obrigatória de alunos e professores nos cursos, salvo programas de educação a distância; a deliberação das universidades quanto às normas de seleção, devendo levar em conta os critérios por ela estabelecidos sobre a orientação do ensino médio; a obrigatoriedade da oferta de cursos noturnos nas IES públicas; o estabelecimento do período letivo; a definição da carga horária mínima de 8 horas semanais de aula para docentes das IES públicas; e a exigência de que os professores do ensino superior devam ter pós-graduação, prioritariamente o mestrado e o doutorado (BRASIL, 1996, p. 75).

Já a estrutura do Ministério da Educação (MEC) é traçada, sobretudo, pela lei 9.131/95, ao passo que a lei 9.135/95 criou o Conselho Nacional de Educação, importante órgão na estrutura do Ensino Superior nacional.

Em relação essa atividade, o MEC é organismo responsável pela coordenação, cabendo-lhe o controle normativo do sistema, o financiamento das Instituições de ensino superior públicas federais (Ifes) e a fiscalização e avaliação destas, assim como das IES privadas, controle exercido através de um vasto conjunto de normas elaboradas 
pelo Conselho Nacional de Educação (CNE) e pela Secretaria de Ensino Superior (SESu), cuja composição envolve a participação de membros da comunidade acadêmica (NEVES, 2002, p. 63-64).

Além do controle normativo, a SESu subsidia o processo de formulação e implementação da Política Nacional para o ensino superior, além de participar ativamente, por meio de sua comissão de especialistas, no processo de supervisão e avaliação das IES, com a finalidade de credenciamento e recredenciamento. (NEVES, 2002, p. 65).

Atualmente, contudo, o principal responsável pela avaliação dos cursos superiores é o Instituto Nacional de Estudos e Pesquisas Educacionais Anísio Teixeira (INEP), autarquia federal (desde 1997) que hoje atua através do Sistema de Avaliação da Educação Superior (SINAES - Lei 10.861/04), formado por três componentes principais: a avaliação das instituições, dos cursos e do desempenho dos estudantes, abrangendo o ensino, a pesquisa e a extensão, além da responsabilidade social, a forma de gestão da instituição, o corpo docente e as instalações.

Os resultados da avaliação realizada pelo INEP permite traçar um panorama da qualidade dos cursos superiores do país e ocorrem mediante a supervisão da Comissão Nacional de Avaliação da Educação Superior (Conaes). As informações permitirão aos órgãos governamentais a orientação das duas decisões quanto aos cursos e instituições de ensino superior no país.

Ou seja, apesar de permitir que IES atuem no ensino superior, o Estado exerce um controle direto sobre suas atividades, regulando a atividade de forma direta e através de um complexo aparato estatal, ainda que a comunidade acadêmica, as instituições órgãos não-governamentais 
sejam ouvidos e participem do processo, tais como o Conselho de Reitores das Universidades Brasileiras (CRUB), a Associação Brasileira de Mantenedoras de Instituições Superiores (ABMES), a Associação Brasileira das Universidades Comunitárias (ABRUC), a Associação Nacional das Universidades Privadas (ANUP) e a Associação Nacional dos Centros Universitários (Anaceu), dentre outras (NEVES, 2002, p.67-69).

\section{A VIABILIDADE DA CRIAÇÃO DE UMA AGÊNCIA INDEPENDENTE PARA REGULAR O ENSINO SUPERIOR NO BRASIL}

A existência de uma vasta gama de regras e procedimentos fiscalizatórios impostos pelo Estado às IES privadas vem gerando um crescente descontentamento por parte desses agentes econômicos que, dentre outros aspectos, alegam que as medidas que norteiam a tomada de decisões no setor são caracterizadas por uma enorme carga de pressão política, o que poderia ser minimizado com a transferência de competências estatais para uma agência reguladora independente, sendo esta uma das premissas que direcionaram a elaboração do Projeto de lei (PL) 4.372 de 2012, proposto pelo Poder Executivo, que cria o Instituto Nacional de Supervisão e Avaliação da Educação Superior (Insaes).

Esse projeto, que no momento da elaboração desse trabalho aguarda apreciação na Comissão de Constituição e Justiça e Cidadania da Câmara dos Deputados já com parecer favorável do relator Deputado Alessandro Molon do PT/RJ, confere ao Insaes a natureza jurídica de autarquia federal, dotando-o de personalidade jurídica de direito público, com autonomia administrativa e financeira, vinculado ao Ministério da 
Educação (art. $\left.1^{\circ}\right)$.

Sua finalidade seria supervisionar e avaliar instituições de educação superior e cursos de educação superior no sistema federal de ensino, e certificar entidades beneficentes que atuem na área de educação superior e básica, competindo ao Insaes, dentre outros:

Art. $3^{\circ}, \mathrm{I}-$ formular, desenvolver e executar as ações de supervisão e avaliação de instituições de educação superior e cursos de educação superior no sistema federal de ensino, de acordo com as diretrizes propostas pelo Ministério da Educação, e em consonância com o Plano Nacional de Educação; II - expedir instruções e estabelecer procedimentos para a aplicação das normas relativas à sua área de competência, de acordo com as diretrizes do Ministério da Educação;

III - autorizar, reconhecer e renovar o reconhecimento de cursos de graduação e sequenciais;

IV - instruir e exarar parecer nos processos de credenciamento e recredenciamentos de instituições de educação superior;

V - acreditar instituições de educação superior e cursos de graduação;

VI - realizar avaliações in loco referentes a processos de credenciamento e recredenciamento de instituições de educação superior e de autorização, reconhecimento e renovação de reconhecimento de cursos de graduação e sequenciais, e diligências para verificação das condições de funcionamento dessas instituições e cursos; e

VII - supervisionar instituições de educação superior e cursos de graduação e sequenciais, quanto ao cumprimento da legislação educacional e à indução de melhorias dos padrões de qualidade da educação superior, aplicando as penalidades e instrumentos previstos na legislação; 
VIII - decretar intervenção em instituições de educação superior e designar interventor, nos termos de lei específica;

[...]. (BRASIL, 1997, p. 1).

Já a direção do Insaes competiria a um Presidente e até seis diretores (de administração, regulação, supervisão, avaliação, tecnologia da informação e de certificação de entidades beneficentes), além de corregedoria, ouvidoria e Procuradoria Federal; contando, ainda, com um Conselho Consultivo, cuja composição e competências seriam definidos em regulamento.

Os servidores da agência, considerando o seu caráter de autarquia em regime especial, submeter-se-iam ao regime estatutário previsto na lei 8.112/90 e seriam, inicialmente, aqueles que já se encontram em exercício na Secretaria de Regulação e Supervisão da Educação Superior no Ministério da Educação. Ou seja, ocorreria uma redistribuição em relação a tais servidores, vedando-se, contudo, a mudança de níveis; além da criação de outros cargos.

O PL 4.372/12 além de disciplinar detalhadamente aspectos relacionados ao quadro de servidores e à avaliação de desempenho do Insaes, traz ainda, no seu capítulo V, um rol de sanções administrativas que a agência reguladora poderá impor aos infratores da legislação educacional, a saber (art. 37):

I. Desativação de cursos e habilitações;

II. Redução do número de vagas autorizadas para o curso;

III. Suspensão temporária de prerrogativas de autonomia da instituição;

IV. Reclassificação da categoria administrativa da instituição; 
V. Descredenciamento institucional;

VI. Advertência aos dirigentes e representantes legais da instituição;

VII. Suspensão dos dirigentes e representantes legais da instituição para o exercício das atividades de gestão institucional por até um ano;

VIII. Inabilitação dos dirigentes e representantes legais para o exercício de atividades de gestão em instituições de educação superior de dois a dez anos; e IX. Multa no valor de R\$ 5 mil a R\$ 500 mil. (BRASIL, 1997, p. 1).

Além desses pontos, nas disposições transitórias, o projeto, propõe uma série de alterações legislativas relacionadas ao patrimônio do Insaes, à criação da Taxa de Avaliação in loco, pelas avaliações periódicas que a agência realizar; assim como à Taxa de Supervisão da Educação Superior, que deverá ser semestralmente recolhida ao Insaes. Por fim, reestrutura as atribuições e composição de vários órgãos do Sistema de Ensino Superior brasileiro.

Dessa reestruturação, destaque-se que ao Insaes caberá a avaliação das instituições, ao passo que o INEP mantém a competência para a avaliação de desempenho dos estudantes.

Na submissão do projeto à Presidência da República, os então Ministros Miriam Belchior, Aloízio Mercadante e Guido Mantega, destacam os desafios sociais a serem enfrentados pelo Brasil enfatizando o papel da educação, sobretudo a partir da análise do Plano Nacional da Educação então em vigor (lei n. 10.172/01) que tem como principal objetivo a elevação do nível global do nível de escolaridade da população como fator preponderante de inclusão social e desenvolvimento humano.

Nessa perspectiva, justificam a definição de um novo marco 
regulatório para a Educação Superior na necessidade de melhoria nos processos de controle da qualidade, através de ações integradas de avaliação, regulação e supervisão das instituições de ensino superior. Destacam os Ministros:

Atualmente, o MEC é responsável pela regulação e supervisão de cerca de 2.667 instituições de educação superior (excluídos deste total as unidades acadêmicas e os campi fora de sede) e 40.748 cursos de graduação nas modalidades presencial e a distância, de acordo com o cadastro de cursos e instituições do E-Mec, sistema eletrônico de acompanhamento processual dos atos de regulação da educação superior. Para isso, são desenvolvidas cerca de 7.000 avaliações in loco por ano, de acordo com dados da Diretoria de Avaliação da Educação Superior do INEP. Com a necessária ampliação da rede de instituições públicas e privadas de educação superior, bem como a de oferta de cursos de graduação para o cumprimento das metas do Novo PNE em relação à educação superior, a capacidade operacional do Ministério para o efetivo exercício dessas atribuições legais de avaliação, regulação e supervisão da educação superior, além de suas muitas outras, estarão inviabilizada. (BRASIL, 2015, p. 3).

Com base nesses fundamentos, apresentaram a proposta de criação do Insaes, que seria responsável pela avaliação in loco das instituições federais e privadas de educação superior e de seus cursos de graduação, atualmente sob a responsabilidade do INEP, buscandose, assim, a integração em um único órgão das atividades de avaliação e supervisão da educação superior.

Como se percebe, o Insaes conta com atribuições inerentes 
às agências reguladoras, tais como regulação, fiscalização, controle e aplicação de sanções, além da capacidade de autofinanciamento, através das Taxas de Avaliação e de Supervisão. Contudo, segundo o projeto 4.372/12 não há a necessidade de aprovação do Senado para a nomeação de sua diretoria, o que, aliás, é uma importante lacuna no projeto, já que não há qualquer menção sobre essa forma de nomeação. Por esses motivos, a doutrina vem classificando referido Instituto como uma agência reguladora atípica. Nesse sentido:

[...] o INSAES nasce como uma agência reguladora atípica, pois prevê a criação de cargos técnicos e apresenta a estrutura e função de uma agência, porém não prevê a autonomia que as agências demandam. Seus diretores são nomeados sem a chancela do Legislativo e não há meio de interlocução com as Instituições de ensino superior reguladas (NUNES; FERNANDES; ALBRECHT, 2012, p. 34).

Ante o exposto, parece inquestionável a necessidade de se regular o ensino superior no Brasil, sobretudo pelo fato de ser um dos raros países em que a educação superior é oferecida, predominantemente, pelo setor privado (BERTERO, 2009, p. 68), cujo crescimento quantitativo nos últimos anos não foi acompanhado, da mesma forma, pelo crescimento qualitativo.

Ou seja, ainda que o Estado tenha deixado de ser o controlador, diretor, planejador e indutor do desenvolvimento, é imperiosa a sua atuação como:

[...] regulador das atividades privatizadas, como balizador da concorrência, como estimulador da oferta de serviços essenciais num ambiente competitivo, 
como garantidor dos direitos do consumidor e como criador de oportunidades de negócios para a iniciativa privada e de investimento para o desenvolvimento tecnológico. (FARIA, 2002, p. 8).

Espera-se, dessa forma, uma rígida atuação do Estado no sentido de regular o setor do Ensino Superior, não apenas numa perspectiva econômica, mas principalmente levando-se em consideração seu viés social, traduzindo-se na "harmonia entre eficiência e equidade de modo que o racional econômico seja conjugado com os valores da justiça social, a fim de viabilizar a eficiência social da regulação.” (BAGNOLI, 2013, p. 115).

É preciso reconhecer a relevância dos agentes econômicos privados na promoção do Ensino Superior no Brasil, mas também exigir deles uma postura comprometida com a qualidade e com a responsabilidade destinadas ao verdadeiro desenvolvimento nacional.

Ou seja, o papel do Estado deve ser no sentido de impedir que o Ensino Superior seja ofertado de forma indiscriminada e pautado exclusivamente pela lógica do mercado, em que o aluno deixa de ser visto nessa perspectiva, passando a ser reconhecido apenas como um consumidor (BERTERO, 2009, p. 70).

Não obstante a necessidade de se reconhecer no Estado um importante papel na regulação da Educação Superior, a proposta de criação de uma agência independente como parece ser o INSAES parece, até o momento, figurar mais como uma retomada do modismo das agências (CUÉLLAR, 2008, p. 41) que propriamente uma alternativa viável para a consolidação de um novo marco regulatório para o setor no Brasil. 
Além de repleto de lacunas, o PL 4.372/12 não apresenta qualquer avanço significativo em relação à regulação do setor já que acaba reunindo na agência reguladora (atípica) atribuições já desenvolvidas por entes que compõem a estrutura do Ministério da Educação.

$\mathrm{O}$ argumento de que uma agência independente poderia retirar da regulação do Ensino Superior a influência política também não é suficiente para justificar a criação do instituto. Isso porque a regulação deve sim ser caraterizada pela conotação política, mas não de um partido ou de um governo (daí muitas críticas a atuação das agências reguladoras na atualidade), mas sim pelas políticas de Estado, entre nós delimitadas nos princípios constitucionais da ordem econômica, delineados no art. 170 da Constituição Federal de 1988.

Por outro lado, o problema de se pensar em criar uma nova agência reguladora, seja no modelo do Instituto Nacional de Supervisão e Avaliação da Educação Superior, seja de uma Agência Nacional de Educação (ANED) (BERTERO, 2009, p. 68) passa pela necessária reflexão acerca do desempenho das agências reguladoras já em funcionamento.

Ou seja, ainda que se opte pela criação de uma agência independente - o que, em si, não é um problema - compete ao Estado, antes de tudo, discutir e delinear o papel que efetivamente se espera das agências reguladoras, aspecto ainda conturbado no cenário político e jurídico nacional, seja através da aprovação de uma lei geral das agências reguladoras (como era o projeto de lei n. 3.337/04 apresentado pelo então Chefe da Casa Civil, José Dirceu), ou por qualquer outro meio que possibilite a consolidação da legitimidade desses entes, afastandoos dos graves riscos decorrentes de sua captura pelos setores regulados o que afeta drasticamente seu papel enquanto instrumento de regulação 
econômica e social.

Em suma, ainda que seja imprescindível a atuação regulatória do Estado na Educação Superior, o que não pode ser apontado como meio de suspender a autonomia universitária, mas tão somente como forma de limitá-la aos objetivos constitucionalmente traçados, a criação de uma agência reguladora independente para esse setor não parece ser, no momento, a medida mais oportuna.

Isso não significa que, em um médio prazo - repensando-se o modelo de agências adotado no Brasil e estabelecendo-se rígidos mecanismos que impeçam a sua captura - não seja viável a transferência de competências do Ministério da Educação para uma agência independente e composta por pessoal qualificado que, representando a sociedade, o Estado e os entes regulados, pautada por uma discricionariedade técnica e com vistas ao desenvolvimento econômico e social, atue na regulação do Ensino Superior.

\section{CONCLUSÃO}

A Constituição Federal de 1988 foi responsável pela reconfiguração do papel do Estado na ordem econômica. Assim, se por um lado limita sua exploração direta de atividade econômica aos imperativos de segurança nacional ou a relevante interesse coletivo (art. 173), por outro lado determina que, na condição de agente normativo e regulador competem ao Estado as funções de fiscalização, incentivo e planejamento (art. 174), delimitando, assim, os contornos do estado-regulador.

Não obstante a previsão constitucional, é com a Reforma do Estado ocorrida nos anos 90 e a consequente superação do modelo de administração burocrática pelo modelo gerencial que culmina essa 
transformação, a partir da qual, pautado pela eficiência (ainda que nem sempre alcançada), o Estado transfere atividades antes por ele desenvolvidas, aos agentes econômicos do setor privado.

Desse novo modelo surgem a agências reguladoras como autarquias em regime especial, caracterizadas por sua independência decorrente, sobretudo, da forma de nomeação de seus diretores bem como da existência de prazo fixo para seus mandatos.

Contudo, a experiência nacional e internacional demonstra que tais agências nem sempre desempenham suas atividades com a independência e autonomia que delas se espera, seja pelas constantes ingerências do Poder Executivo sobre suas atividades, seja pela interferência dos setores regulados na tomada de decisão por parte das agências, fenômenos a que a doutrina trata como "captura".

Essas circunstâncias, por si só, conduzem à necessidade de se repensar o modelo de agências reguladoras adotado no Brasil, de forma a conferir-lhes maior legitimidade e independência frente aos setores privados e ao poder público para que tais autarquias consolidem-se, efetivamente, como instrumentos de regulação pautados por uma política de Estado e não de governos.

Nessa perspectiva é que se discute a necessidade e a viabilidade de se criar uma agência independente para regular a Educação Superior no Brasil, discussões hoje voltadas para o Projeto de lei 4.372/12 que já conta com parecer favorável do relator na Comissão de Constituição e Justiça e de Cidadania da Câmara dos Deputados, após já ter sido aprovada pela Comissão de Educação da mesma Casa Legislativa.

É notória a necessidade de atuação do Estado na regulação do Ensino Superior, setor majoritariamente ocupado por instituições privadas, cujo crescimento quantitativo nas últimas décadas não 
corresponde ao crescimento qualitativo. Nesse sentido, mais que alcançar metas de inclusão de jovens no ensino superior, compete ao Estado zelar para que essa formação seja solidamente alcançada de forma a que a condução do setor não se dê exclusivamente sob a lógica do mercado, permitindo que além do papel de consumidor, ao aluno, seja respeitada a condição de cidadão, responsável pelo desenvolvimento social, cultural e econômico do país.

Contudo, não obstante a necessidade de o Estado limitar, através da regulação, a autonomia dos agentes econômicos que atuam no ensino superior, entende-se que a criação de uma agência reguladora atípica como o Instituto Nacional de Supervisão e Avaliação da Educação Superior ou mesmo de uma agência típica (eventualmente chamada de Aned - Agência Nacional de Educação) não mostra-se oportuna no momento presente.

Antes de se criar um novo ente, e de forma a se evitar o risco de que se volte ao "modismo" das agências reguladoras, é preciso que se discuta e se compreenda melhor qual é o papel que o Estado brasileira espera de tais autarquias, sobretudo em relação à sua legitimidade e aos limites de sua atuação, seja em relação aos setores privados, seja em relação às competências do Poder Legislativo e do Judiciário.

Sustenta-se, enfim, que apesar de competir ao Estado a regulação do Ensino Superior, no momento, a criação de uma nova agência não é a melhor alternativa, devendo-se manter a atividade regulatória sob competência do Ministério da Educação, pelo menos até que haja uma compreensão adequada de qual seria o papel dessa nova agência reguladora, já que o PL 4.372/12 não foi capaz de dirimir tais incertezas nem, tampouco, justificar a necessidade de descentralização da atividade reguladora estatal. 


\section{REFERÊNCIAS}

ALEXANDRINO, Marcelo; PAULO, Vicente. Direito administrativo descomplicado. 21. ed. São Paulo: Método, 2013.

ARAGÃO, Alexandre Santos. Agências reguladoras e a evolução do direito administrativo econômico. Rio de Janeiro: Forense, 2006.

BAGNOLI, Vicente. Direito econômico. 6.ed. São Paulo: Atlas, 2013.

. Direito e poder econômico: os limites jurídicos do

Imperialismo frente aos limites econômicos da soberania. Rio de Janeiro: Elsevier, 2009.

BARROSO, Luis Roberto. Constituição e ordem econômica e agências reguladoras. Revista Eletrônica de Direito Administrativo Econômico, Salvador, Instituto de Direito Público da Bahia, n. 3, fev. mar.abr. 2005. Disponível em: <http://direitodoestado.com.br>. Acesso em: 27 out. 2013.

BELCHIOR, Miriam Aparecida; OLIVA, Aloízio Mercadante; MANTEGA, Guido. EMI 00199/2012 MP/MEC/MF. Disponível em: http://www.planalto.gov.br/ccivil_03/Projetos/ExpMotiv/EMI/2012/199\%20 -\%20MP\%20MEC\%20MF.htm>. Acesso em: 17 maio 2015.

BERTERO, Carlos Osmar. Agência Nacional de Educação. In: GV Executivo, São Paulo, v. 8, n. 1. p. 66-71, 2009. Disponível em: $<$ http://bibliotecadigital.fgv.br/ojs/index.php/gvexecutivo/article/view/23898>. Acesso em: 25 abr. 2015.

BERCOVICI, Gilberto. Constituição econômica e desenvolvimento: uma leitura a partir da Constituição de 1988. São Paulo: Malheiros, 2005.

BRASIL. Constituição (1988). Constituição da República Federativa do Brasil. Brasília: Senado Federal, 1988. Disponível em: < https:// www.planalto.gov.br/ccivil_03/constituicao/constituicao.htm>. Acesso em: 16 jun. 2016. 
. Ministério de Educação e Cultura. LDB - Lei no 9394/96, de 20 de dezembro de 1996. Estabelece as diretrizes e bases da Educação Nacional. Brasília : MEC, 1996.

. Secretaria de Assuntos Parlamentares. Projeto de lei. Cria o Instituto Nacional de Supervisão e Avaliação da Educação Superior - INSAES, e dá outras providências. Brasília: Senado Federal, 1997. Disponível em: http://www.planalto.gov.br/ccivil 03/Projetos/ PL/2012/msg398-31agosto2012.htm>. Acesso em: 10 maio 2016.

. Subchefia de Assuntos Parlamentares. EMI 00199/2012 MP/ $\overline{\mathrm{MEC} / \mathrm{M}}$. Brasília, 2012. Disponível em: http://www.planalto.gov. br/ccivil_03/Projetos/ExpMotiv/EMI/2012/199\%20-\%20MP\%20 MEC\%20MF.htm>. Acesso em: 09 jun. 2016.

CARVALHO FILHO, José dos Santos. Manual de direito administrativo. 27.ed. São Paulo: Atlas, 2014.

CENSO DA EDUCAÇÃO SUPERIOR 2012: resumo técnico. Brasília: Instituto Nacional de Estudos e Pesquisas Educacionais Anísio Teixeira, 2014. Disponível em: http://download.inep.gov.br/ download/superior/censo/2012/resumo_tecnico_censo_educacao_ superior_2012.pdf >. Acesso em: 1maio 2015.

CUÉLLAR, Leila. Introdução às agências reguladoras brasileiras. Belo Horizonte: Fórum, 2008.

DEL MASSO, Fabiano. Direito econômico esquematizado. 2.ed. São Paulo: Método, 2013.

FARIA, José Eduardo (Org.). Regulação, direito e democracia. São Paulo: Fundação Perseu Abramo, 2002.

GRAU, Eros Roberto. A ordem econômica na Constituição de 1988. 12.ed. São Paulo: Malheiros, 2007.

MENDES, Gilmar Ferreira; COELHO, Inocêncio Mártires; 
BRANCO, Paulo Gustavo Gonet. Curso de direito constitucional. 4. ed. São Paulo: Saraiva, 2009.

MOREIRA NETO, Diogo de Figueiredo. Direito regulatório. Rio de Janeiro: Renovar, 2003.

NOHARA, Irene Patrícia. Direito administrativo. São Paulo: Atlas, 2011.

. Reforma administrativa e burocracia: impacto da eficiência na configuração do direito administrativo brasileiro. São Paulo: Atlas, 2012.

NEVES, Clarissa Eckert Baeta. A Estrutura e o funcionamento do ensino superior no Brasil. In: SOARES, Maria Susana Arrosa (Coord.). Educação Superior no Brasil. Brasília: CAPES, 2002. p. 43-106.

NUNES, Edson de Oliveira; FERNANDES, Ivanildo; ALBRECHT, Julia Vogel. O INSAES como agência reguladora atípica. Bento Gonçalves, RS: Observatório, 2012. Disponível em <http:// www.observatoriouniversitario.org.br/documentos_de_trabalho/ documentos_de_trabalho_104.pdf $>$. Acesso em: $2 \overline{7}$ abr. 2015.

OLIVEIRA, Rafael Carvalho Rezende. O modelo norte-americano de agências reguladoras e sua recepção pelo Direito Brasileiro. Revista da EMERJ, Rio de Janeiro, v. 12, n. 47, 2009. p. 157-176.

SCHIRATO, Vitor Rhein. As agências reguladoras independentes e alguns elementos da teoria geral do Estado. In: ARAGÃO, Alexandre Santos de; MARQUES NETO, Floriano de Azevedo. Direito administrativo e seus novos paradigmas. Belo Horizonte: Fórum, 2012. p. 469-537.

SILVA, José Afonso da. Comentário contextual à Constituição. São Paulo: Malheiros, 2009.

SILVA JR., João dos Reis; SGUISSARDI, Valdemar. Novas faces da educação superior no Brasil. São Paulo: Cortez, 2001. 